\title{
Vinyl Pivalate Propagation Kinetics in Radical Polymerization
}

\author{
Otlaatla Monyatsi, Robin A. Hutchinson* \\ Department of Chemical Engineering, Dupuis Hall, \\ Queen's University, Kingston, Ontario K7L 3N6, Canada \\ E-mail: robin.hutchinson@queensu.ca; FAX: 1-613-533-6637
}

\begin{abstract}
Radical propagation kinetics of the bulk homopolymerizations of vinyl pivalate (VPi) and vinyl benzoate $(\mathrm{VBz})$ have been studied using pulsed-laser polymerization (PLP) combined with size exclusion chromatography (SEC). As part of the study, the Mark-Houwink parameters of poly(VPi) and poly(VBz) in tetrahydrofuran were determined using a triple detector SEC. The observed significant increase (by approximately 20\%) of the bulk VPi propagation rate coefficient $\left(k_{\mathrm{p}}\right)$ as pulse repetition rate is increased from 200 to $500 \mathrm{~Hz}$ is similar to that reported for vinyl acetate (VAc). Data collected in the temperature range of 25 to $85^{\circ} \mathrm{C}$ for VPi is well fit by the Arrhenius relation $\ln \left(k_{\mathrm{p}} / \mathrm{L} \cdot \mathrm{mol}^{-1} \cdot \mathrm{s}^{-1}\right)=15.73-2093(T / \mathrm{K})$. The activation energy is similar to that found for vinyl acetate (VAc), with $k_{\mathrm{p}}$ values higher by $\sim 50 \%$. PLP studies in ethyl acetate and in heptane found no substantial solvent effect on VPi or VAc $k_{\mathrm{p}}$ values. Attempts to measure the propagation kinetics of VBz by PLP were not successful, suggesting that significant radical stabilization occurs for the system. Small-scale batch polymerization experiments demonstrated relative polymerization rates of these vinyl ester monomers that are consistent with the PLP results.
\end{abstract}




\section{Introduction}

Production of existing and new polymer grades requires well-detailed understanding of polymerization kinetics and mechanisms, to aid process development and the optimization of product properties and operating conditions. The determination of individual kinetic coefficient such as the chain growth rate coefficient of radical polymerization, $k_{\mathrm{p}}$, is required to enable modeling of these systems.

In 1987 Olaj and co-workers introduced a novel experimental method, pulsed-laser polymerization coupled with Size Exclusion Chromatography (PLP-SEC), to directly estimate $k_{\mathrm{p}}$, from the molar mass distribution (MMD) analysis of the resulting polymer. ${ }^{[1]}$ This technique has been recommended as the method of choice for determination of $k_{\mathrm{p}}$ by the IUPAC subcommittee on Modeling of Polymerization Kinetics and Process for its reliability and ease of use. ${ }^{[2]}$ Since its introduction, a series of benchmark papers have been published providing best-fit Arrhenius parameters to data collected in multiple labs over a broad temperature range for styrene, methacrylates and acrylates. ${ }^{[3-8]}$ However, there is less data available for the vinyl ester family of monomers, other than vinyl acetate (VAc) ${ }^{[9-11]}$ and an early study of vinyl decanoate. $^{[12]}$ Kubota et al. determined the $k_{\mathrm{p}}$ of vinyl pivalate (VPi, IUPAC: ethenyl 2,2dimethylpropanoate) in heptane using Electron Paramagnetic Resonance (EPR ${ }^{[13]}$ to quantify the radical concentration, reporting estimated Arrhenius parameters of $A=1.39 \times 10^{7} \mathrm{~L} \cdot \mathrm{mol}^{-1} \cdot \mathrm{s}^{-1}$ and $E_{\mathrm{a}}=20.5 \mathrm{~kJ} \cdot \mathrm{mol}^{-1}$ for data collected between 9 and $93^{\circ} \mathrm{C}$; the $k_{\mathrm{p}}$ value of $6750 \mathrm{~L} \cdot \mathrm{mol}^{-1} \cdot \mathrm{s}^{-1}$ at $50^{\circ} \mathrm{C}$ is similar to that reported for VAc $\left(6600-8000 \mathrm{~L} \cdot \mathrm{mol}^{-1} \cdot \mathrm{s}^{-1}\right.$ at $\left.50{ }^{\circ} \mathrm{C}\right)$, as is the activation energy $\left(20.9-21.8 \mathrm{~kJ} \cdot \mathrm{mol}^{-1}\right) \cdot{ }^{[10-11]}$ This finding is perhaps a bit surprising, as the $k_{\mathrm{p}}$ values of alkyl acrylates and methacrylates increase with increasing size of the ester group in bulk. ${ }^{[5]}$ The 
difference may perhaps be related to the use of heptane in the EPR study, as small but significant solvent effects on propagation kinetics are reported. ${ }^{[14]}$

A complicating factor in the propagation kinetics of vinyl esters is the occurrence of head-tohead additions, on the order of $1-2 \%$, as first reported by Flory et al. for VAc. ${ }^{[15]}$ Indeed, the increased stability of the $\mathrm{CH}_{2}$ adduct resulting from the inverted addition leads to a reduced rate of reaction when conducting controlled radical polymerization (CRP) of VAc. ${ }^{[16]}$ Recently, CRP of VPi has been studied by Islam et al.:;17] although some control was achieved, difficulty in narrowing the polymer dispersity was attributed to the lack of a conjugating substituent found in styrene and methacrylates, with the high reactivity of the VPi radicals hypothesized to increase the importance of termination and chain transfer reactions. ${ }^{[17]}$ Similar factors were initially believed to be the main difficulty in the study of propagation studies of VAc by PLP-SEC ${ }^{[18]}$ Junkers et al. suggested that the influence of intramolecular chain transfer (backbiting) in the VAc system led to an increase in measured (apparent) $k_{\mathrm{p}}$ values by $25 \%$ as pulse repetition rate (p.r.r.) increased from 100 to $500 \mathrm{~Hz}$. However, an EPR study by Kattner and Buback conclusively showed that VAc does not undergo backbiting, as proven by the lack of midchain radicals in the system. ${ }^{[19]}$ Most recently, Monyatsi et al. conducted an experimental PLP study of VAc combined with simulation; ${ }^{[10]}$ the same increase in $k_{\mathrm{p}}$ with p.r.r. was found (as reported by Junkers) with an alternative explanation for the behavior proposed, the effect of head-to-head addition. 

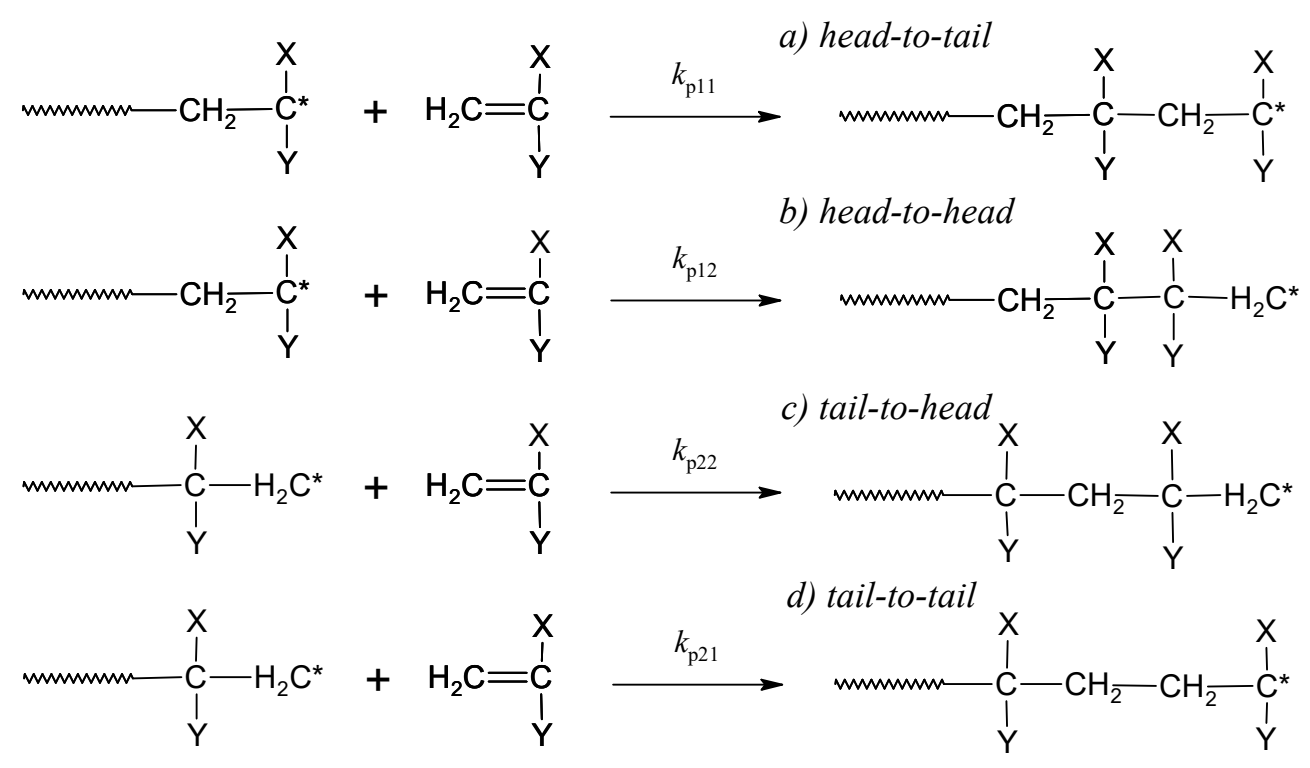

Figure 1. Possible routes for monomer addition during radical polymerization of vinyl esters ${ }^{[10]}$

Head-to-head addition is one of the four possible routes for monomer addition during polymerization, as illustrated in Figure 1. Equation (1) has been derived for the average chain growth propagation rate coefficient, $k_{\mathrm{P}}^{\mathrm{av}}$, using the individual rate coefficients for the four possible monomer additions, with subscripts 1 and 2 referring to tail and head radicals, respectively. ${ }^{[10]}$ Depending upon the value of $\mathrm{k}_{\mathrm{p} 21}$ (tail-to-tail addition), simulations indicate that the occurrence of $1-2 \%$ of head-to-head additions $\left(\mathrm{k}_{\mathrm{p} 12} / \mathrm{k}_{\mathrm{p} 11}=0.01-0.02\right)$ is sufficient to cause the PLP-determined value to show a dependence of p.r.r. not seen for most monomers, such as methacrylates, which only propagate by head-to-tail addition.

$$
k_{\mathrm{p}}^{\mathrm{av}}=k_{\mathrm{p} 11}-\frac{k_{\mathrm{p} 11}-k_{\mathrm{p} 22}-2 k_{\mathrm{p} 21}}{1+\frac{k_{\mathrm{p} 21}}{k_{\mathrm{p} 12}}}
$$

There is evidence that head-to-head addition also influences the propagation kinetics of other vinyl esters. Hayashi and Otsu determined that approximately 1-2\% head-to-head addition occurs 
during polymerization of many vinyl ester monomers including VAc, vinyl valerate, vinyl butyrate, and vinyl benzoate. ${ }^{[20]}$ Thus, it is possible that the study of chain growth kinetics of these monomers by the PLP-SEC technique will also be influenced. In this work, we present a comprehensive study of free radical polymerization kinetics of VPi using PLP-SEC, investigating the effect of pulse repetition rate on $k_{\mathrm{p}}$ between $25-85^{\circ} \mathrm{C}$. As part of the study, the Mark-Houwink (M-H) parameters and the polymer $\mathrm{d} n / \mathrm{d} c$ value required for SEC analysis for polyvinyl pivalate and polyvinyl benzoate were also determined.

\section{Experimental Section}

Vinyl pivalate (VPi, Aldrich 99\%), vinyl benzoate (VBz, Aldrich $\geq 99 \%$ ), vinyl acetate (VAc, Aldrich, 99+\%), benzoin (Aldrich $\geq 99.5 \%$ ), methanol (MeoH, reagent grade, ACP Chemicals Inc.), acetone (reagent grade, ACP Chemicals Inc.), heptane (Aldrich 99\%) and ethyl acetate (EAc, Caledon Labs) was used as received. The experimental set up and procedure is similar to previous PLP studies. ${ }^{[9-11,21]}$ Low monomer conversion $(<2 \%)$ of bulk VPi was generated using a pulsed laser setup consisting of a Xantos XS-500 laser operating at a wavelength of 351nm, 3-15 ns pulse duration and pulse energy of 3-8 $\mathrm{mJ} /$ pulse. Bulk monomer VPi solution with 5 $\mathrm{mmol} \cdot \mathrm{L}^{-1}$ benzoin photo-initiator was prepared, and approximately $3 \mathrm{~mL}$ of the monomer mixture was added to a quartz cuvette and allowed to reach the desired temperature $\left( \pm 0.5^{\circ} \mathrm{C}\right)$ before being exposed to the laser light. The experiments were run at a constant pulse repetition rate (p.r.r.) monitored between 100 and $500 \mathrm{~Hz}$ in a temperature range of 25 to $85{ }^{\circ} \mathrm{C}$. The residual VPi content was reduced from the samples under an air stream and the resulting mixture was precipitated in methanol. The heterogeneous mixture was allowed to settle overnight in a freezer, the liquid was decanted from the mixture and the remaining polymer precipitate dried under vacuum. The same procedure was followed for bulk VBz experiments (with 1, 5 and 20 
$\mathrm{mmol} \cdot \mathrm{L}^{-1}$ of benzoin photoinitiator, p.r.r. between 2 and $500 \mathrm{~Hz}$, and temperature between 25 and $90{ }^{\circ} \mathrm{C}$ ), and for VAc and VPi experiments conducted in the presence of $50 \mathrm{vol} \%$ heptane or ethyl acetate solvent.

The molar mass distribution (MMDs) of the samples produced were analyzed using an SEC system consisting of a Water 2960 separation module, an auto injector, and two detectors: a Waters 410 differential refractometer (DRI) and a Wyatt Dawn EOS $690 \mathrm{~nm}$ Laser Photometer (LS). The system used distilled THF as an eluent, programmed at a flow rate of $0.3 \mathrm{~mL} \cdot \mathrm{min}^{-1}$ through four Styragel® THF columns $(\mathrm{HR} 0.5,1,3,4)$ maintained at $35^{\circ} \mathrm{C}$. The DRI detector was calibrated using narrow polystyrene standards with molecular weight ranging from 370$8.6 \times 10^{5} \mathrm{Da}$. The MMDs of the PLP samples were estimated using the principle of universal calibration, with the Mark-Houwink (M-H) parameters summarized in Table 1; the poly(VPi) and poly(VBz) values were determined as part of this study. Moreover, the density of VPi monomer was also determined between 25 and $70{ }^{\circ} \mathrm{C}$ using a Paar DMA 48 Density Meter, with linear fit parameters also summarized in Table 1.

The poly(VPi) MMDs were smoothed and differentiated using OriginLab software, with $k_{\mathrm{p}}$ estimated using the position of the $1^{\text {st }}$ inflection point $\left(M_{\mathrm{o}}\right)$ taken as the maximum from the firstderivative plot, monomer density $\left(\rho_{\text {mon }}\right)$ calculated at reaction temperature, monomer volume fraction $\left(\phi_{\text {mon }}\right)$ in the case of solution experiments, and the time between pulses $\left(t_{\mathrm{o}}\right)$ as illustrated in equation $(2){ }^{[1]}$

$$
k_{\mathrm{p}}=\frac{M_{\mathrm{o}}}{1000 \phi_{\mathrm{mon}} p_{\mathrm{mon}} t_{\mathrm{o}}}
$$


In order to check the validity and accuracy of DRI results, LS detector results for some samples were analyzed using the $\mathrm{d} n / d c$ value of poly(VPi) (Table 1), also measured in this work. Several polymer samples produced by PLP at $100-500 \mathrm{~Hz}$ p.r.r. were used to prepare 4-6 polymer solutions with concentrations between $0.2-15 \mathrm{mg} \cdot \mathrm{mL}^{-1}$; these samples were injected sequentially to a Wyatt Optilab DSP refractometer at $690 \mathrm{~nm}$ calibrated using sodium chloride to create a curve with slope $\mathrm{d} n / \mathrm{d} c$. The graphs and individual estimates (between 0.051 and $0.058 \mathrm{~mL} \cdot \mathrm{g}^{-1}$ ) are shown in Supporting Information, with the average value of $0.054 \mathrm{~mL} \cdot \mathrm{g}^{-1}$ used to process the poly(VPi) MMDs measured by light scattering.

The M-H parameters of poly(VPi) (samples also prepared using PLP at $100-500 \mathrm{~Hz}$ p.r.r.) were estimated using a triple detector Viscotek SEC described by Nerkar et al. ${ }^{[22]}$ The parameters were determined from processing the intrinsic viscosity and light scattering output with the OmniSEC software using the average $\mathrm{d} n / \mathrm{d} c$ value of poly(VPi) reported earlier. The M-H plots obtained for the four samples are included as Supporting Information, with Table 1 summarizing the estimated M-H parameters. While there is some scatter in the individual $K$ and $a$ values due to their high correlation, the calculated values of intrinsic viscosity for polymer with $M=10^{5} \mathrm{Da}$ are in reasonable agreement $\left(0.406-0.435 \mathrm{dL} \cdot \mathrm{g}^{-1}\right)$. Figure 2 illustrates the ability of the global fit values, $K=1.75 \times 10^{-4} \mathrm{dL} \cdot \mathrm{g}^{-1}$ and $a=0.676$, to represent the individual experiments. $\mathrm{M}-\mathrm{H}$ parameters for poly(VAc) (prepared using PLP at a p.r.r. of $100 \mathrm{~Hz}$ ) were also measured as part of this study, to check the accuracy of our setup. As summarized in Table 1, the parameters for poly(VAc) in THF are close to previous literature, thus validating the methodologies used to estimate the $\mathrm{M}-\mathrm{H}$ parameters for poly(VPi). It is also interesting to note that the $\mathrm{M}-\mathrm{H}$ plot for poly (VAc) is parallel (at slightly higher intrinsic viscosity) to that of poly(VPi) (Figure 2),. 
The same procedures for determining $\mathrm{d} n / \mathrm{d} c$ and $\mathrm{M}-\mathrm{H}$ parameters were used for poly(VBz), with the graphs shown in Supporting Information, and the average $\mathrm{d} n / \mathrm{d} c$ value and the $\mathrm{M}-\mathrm{H}$ parameters reported in Table 1 and plotted in Figure 1.

Table 1. Parameters used to interpret PLP-SEC results for determine of propagation kinetic parameters.

\begin{tabular}{|c|c|c|c|c|c|c|c|}
\hline \multirow[b]{2}{*}{ Monomer } & \multirow[b]{2}{*}{$\rho\left(\mathrm{g} \cdot \mathrm{mL}^{-1}\right)$} & \multirow[b]{2}{*}{$d n / d c\left(\mathrm{~mL} \cdot \mathrm{g}^{-1}\right)$} & \multirow[b]{2}{*}{ Polymer } & \multicolumn{4}{|c|}{ Mark-Houwink parameters } \\
\hline & & & & $K\left(\mathrm{dL} \cdot \mathrm{g}^{-1}\right) \times 10^{-4}$ & $a$ & {$[\eta]=K(M)^{a^{* *}}$} & Ref. \\
\hline Styrene & - & 0.185 & & 1.14 & 0.716 & 0.433 & 9 \\
\hline \multirow{3}{*}{ VAc } & \multirow{3}{*}{$0.9584-0.00133 \mathrm{~T} /{ }^{\circ} \mathrm{C}^{[18]}$} & \multirow{3}{*}{0.058} & Set 1 & 1.56 & 0.708 & 0.541 & 9 \\
\hline & & & Set 2 & 2.24 & 0.674 & 0.525 & 9 \\
\hline & & & $100 \mathrm{~Hz}$ & 2.72 & 0.661 & 0.550 & $*$ \\
\hline \multirow{5}{*}{ VPi } & \multirow{5}{*}{$0.8933-0.00111 \mathrm{~T} /{ }^{\circ} \mathrm{C}^{*}$} & \multirow{5}{*}{0.054} & $100 \mathrm{~Hz}$ & 2.45 & 0.645 & 0.412 & $*$ \\
\hline & & & $250 \mathrm{~Hz}(\mathrm{i})$ & 1.16 & 0.715 & 0.435 & $*$ \\
\hline & & & $250 \mathrm{~Hz}$ (ii) & 1.67 & 0.682 & 0.431 & $*$ \\
\hline & & & $500 \mathrm{~Hz}$ & 1.99 & 0.662 & 0.406 & $*$ \\
\hline & & & Global & 1.75 & 0.676 & 0.421 & $*$ \\
\hline $\mathrm{VBz}$ & $1.0821-0.0007 \mathrm{~T} /{ }^{\circ} \mathrm{C}^{[23]}$ & 0.1527 & & 1.53 & 0.648 & 0.265 & $*$ \\
\hline
\end{tabular}

*parameters estimated in this work, **calculated for equivalent $\mathrm{MW}$ of $10^{5} \mathrm{Da}$ 


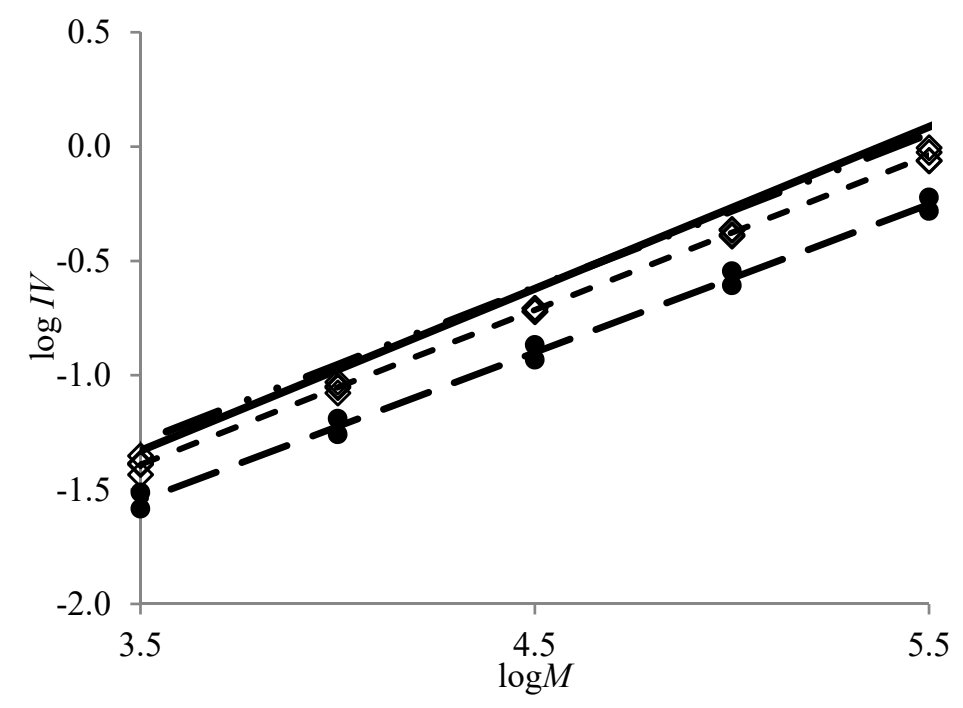

Figure 2. $\log -\log$ plot of intrinsic viscosity vs. $M$ for poly(VPi) $(\diamond,---)$ and poly $(\mathrm{VBz})(\bullet,--$ -). Points are exported data, the lines drawn using best-fit Mark-Houwink parameters as reported in Table 1. Reference lines for poly(VAc) (-, - - - ) plotted using literature M-H parameters (see Table 1).

\section{Results and Discussion}

The propagation kinetics of bulk VPi was studied by PLP-SEC between 25 and $85{ }^{\circ} \mathrm{C}$ using benzoin photoinitiator with p.r.r. between 100 and $500 \mathrm{~Hz}$, with the complete set of experimental data obtained tabulated as Supporting Information. Representative MMDs and first-derivative plots are shown in Figure 3. It can be observed that the MMDs and the corresponding inflection points (as seen on the first-derivative curves) shift to the right as the p.r.r. decreases, as expected. Both first and second inflection points are clearly seen for most cases, with the second inflection point at approximately twice the $M_{\mathrm{o}}$ value, as expected. ${ }^{[9,18]}$ As illustrated in Figure 3, the poly(VPi) MMDs become more structured as the p.r.r. increases. At $100 \mathrm{~Hz}$, the MMD is broader and the $2^{\text {nd }}$ inflection point cannot be identified at $50^{\circ} \mathrm{C}$ and higher. 

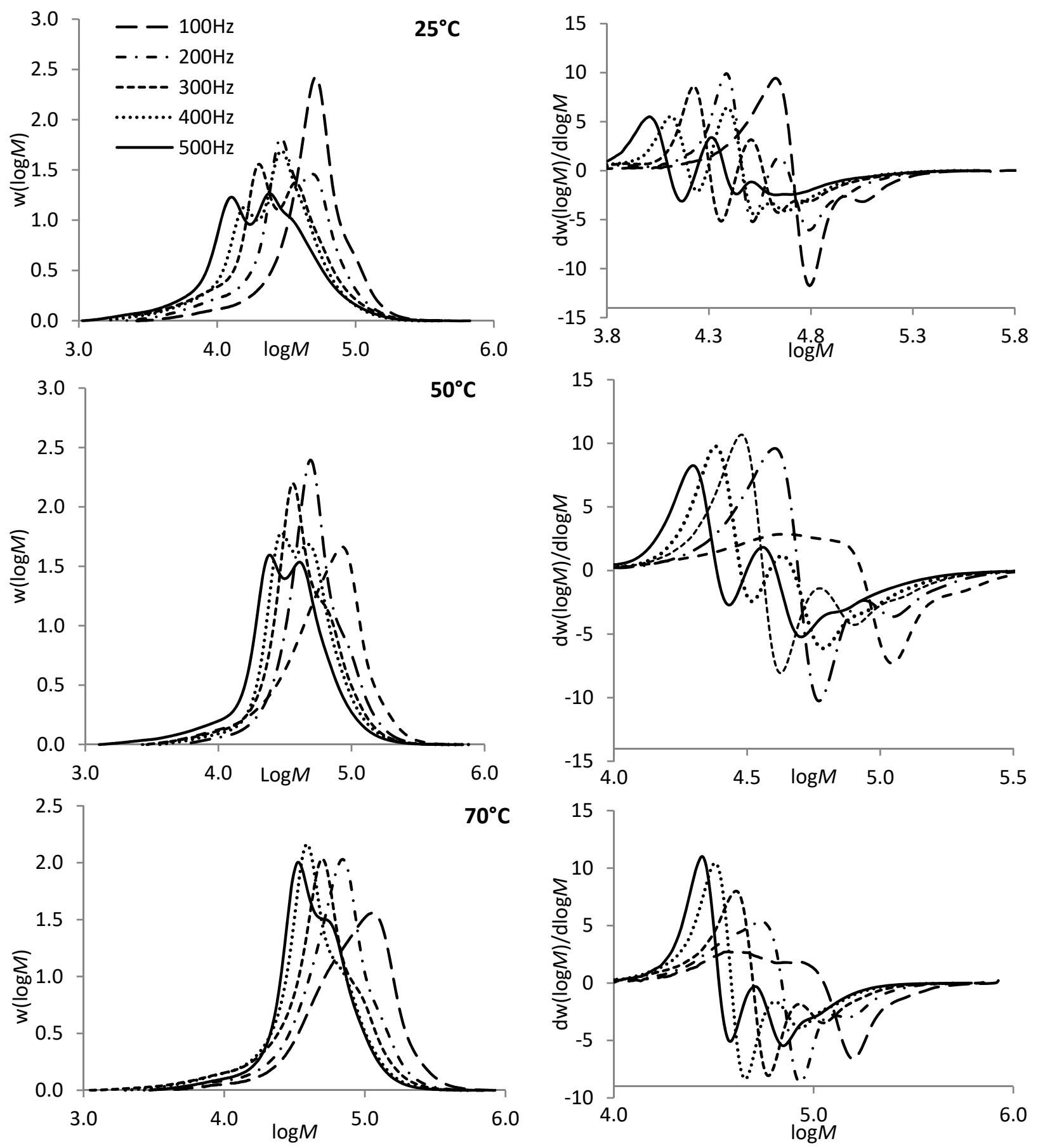

Figure 3. MMDs (left) and corresponding first derivative plots (right) for poly(VPi) produced by PLP at $100-500 \mathrm{~Hz}$ pulse repetition rate at 25 (top), 50 (middle), and 70 (bottom) ${ }^{\circ} \mathrm{C}$. 
The resulting values of the propagation coefficient, $k_{\mathrm{p}}$, were determined from equation (2) using the measured $M_{\mathrm{o}}$ values. At $50{ }^{\circ} \mathrm{C}, k_{\mathrm{p}}$ increased from 9400 to $11300 \mathrm{~L} \cdot \mathrm{mol}^{-1} \cdot \mathrm{s}^{-1}$ as the p.r.r. increased from 200 to $500 \mathrm{~Hz}$. This trend, seen at all temperatures, is compared to our previous results for $\mathrm{VAc}^{[10]}$ in Figure 4. As shown in Figure 5, the PLP-generated MMDs of both polymers have a similar shape with clear $1^{\text {st }}$ and $2^{\text {nd }}$ inflection points, with the poly (VPi) inflection points at a higher $M_{\mathrm{o}}$ for the same p.r.r. Two important points can be noted from these results. First, the absolute $k_{\mathrm{p}}$ values determined by PLP-SEC are higher for VPi than VAc, a result to be discussed later. Second, the $\sim 20 \%$ increase in apparent $k_{\mathrm{p}}$ values measured with increasing p.r.r. for VPi is of similar magnitude as the increase reported for VAc. ${ }^{[10-11]}$

As done for the VAc study, the systematic variation in $k_{\mathrm{p}}$ was further explored by constructing separate Arrhenius fits for the VPi results obtained at each p.r.r., as shown in Figure 6 with the corresponding parameters summarized in Table 2 . There was insufficient data to construct a plot for the p.r.r. of $100 \mathrm{~Hz}$, due to the lack of reliable data (no $2^{\text {nd }}$ inflection points) for $\mathrm{T} \geq 50{ }^{\circ} \mathrm{C}$. As well as the increasing $k_{\mathrm{p}}$ values with p.r.r., the activation energy $\left(E_{\mathrm{a}}\right)$ for VPi also increased slightly, from 16.0 to $18.9 \mathrm{~kJ} \cdot \mathrm{mol}^{-1}$ between 200 and $500 \mathrm{~Hz}$.

Table 2. Arrhenius parameters obtained from linear fitting of $\ln \left(k_{\mathrm{p}}\right)$ values estimated from PLPSEC experiments for bulk VPi conducted between 25 and $85^{\circ} \mathrm{C}$. Separate fits were conducted at each pulse repetition rate.

\begin{tabular}{llllc}
\hline Repetition rate $(\mathrm{Hz})$ & \multicolumn{1}{c}{$\ln (A)$} & $E_{\mathrm{a}} / R(\mathrm{~K})$ & $E_{\mathrm{a}}\left(\mathrm{kJmol}^{-1}\right)$ & $k_{\mathrm{p}}\left(\right.$ at $\left.50^{\circ} \mathrm{C}\right)$ \\
\hline 200 & $15.11 \pm 0.27$ & $1922 \pm 87$ & 16.0 & 9531 \\
300 & $15.53 \pm 0.23$ & $2034 \pm 74$ & 16.9 & 10257 \\
400 & $15.91 \pm 0.23$ & $2142 \pm 74$ & 17.8 & 10738 \\
500 & $16.37 \pm 0.36$ & $2274 \pm 115$ & 18.9 & 11305 \\
$200-500$ & $15.73 \pm 0.25$ & $2093 \pm 81$ & 17.4 & 10437 \\
EPR technique $^{[13]}$ & 16.45 & 2466 & 20.5 & 6748 \\
$50-100^{[24]}$ & 16.29 & 2321 & 19.3 & 9031 \\
\hline
\end{tabular}




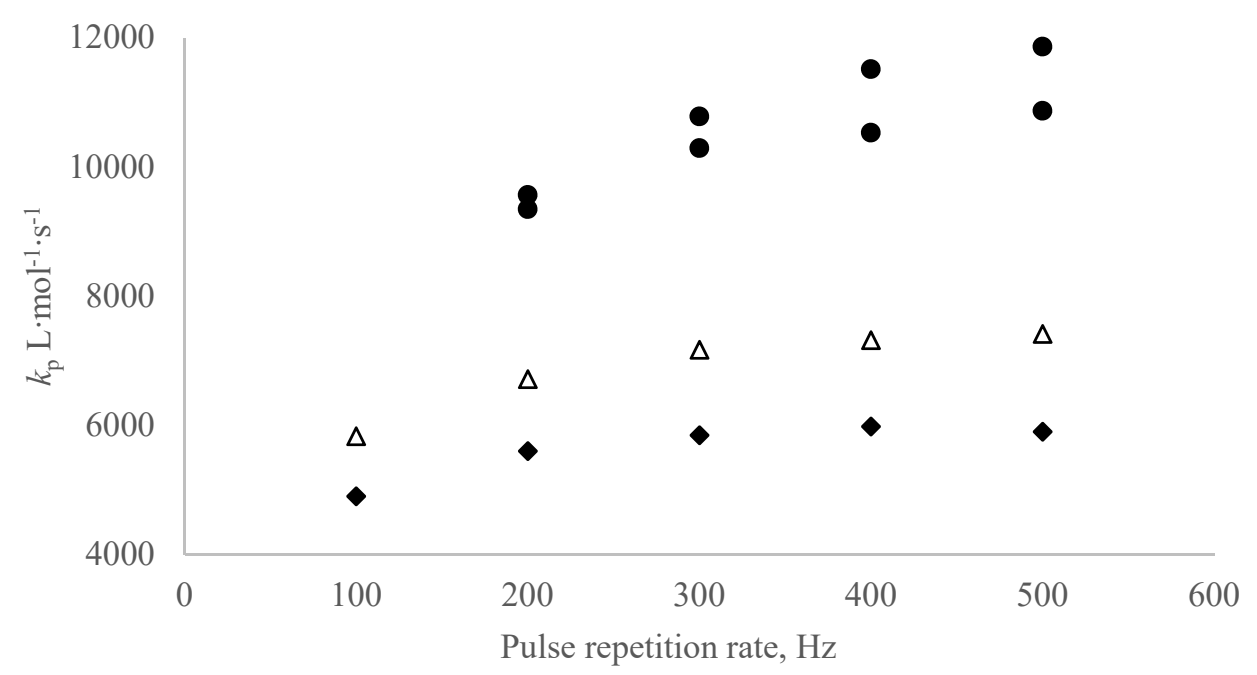

Figure 4. $k_{\mathrm{p}}$ vs. pulse repetition rate for VPi PLP-SEC experiments at $25(\bullet)$ and $50{ }^{\circ} \mathrm{C}(\bullet)$ and VAc PLP-SEC experiments at $50^{\circ} \mathrm{C}(\Delta)^{[10]}$ with benzoin photoinitiator.
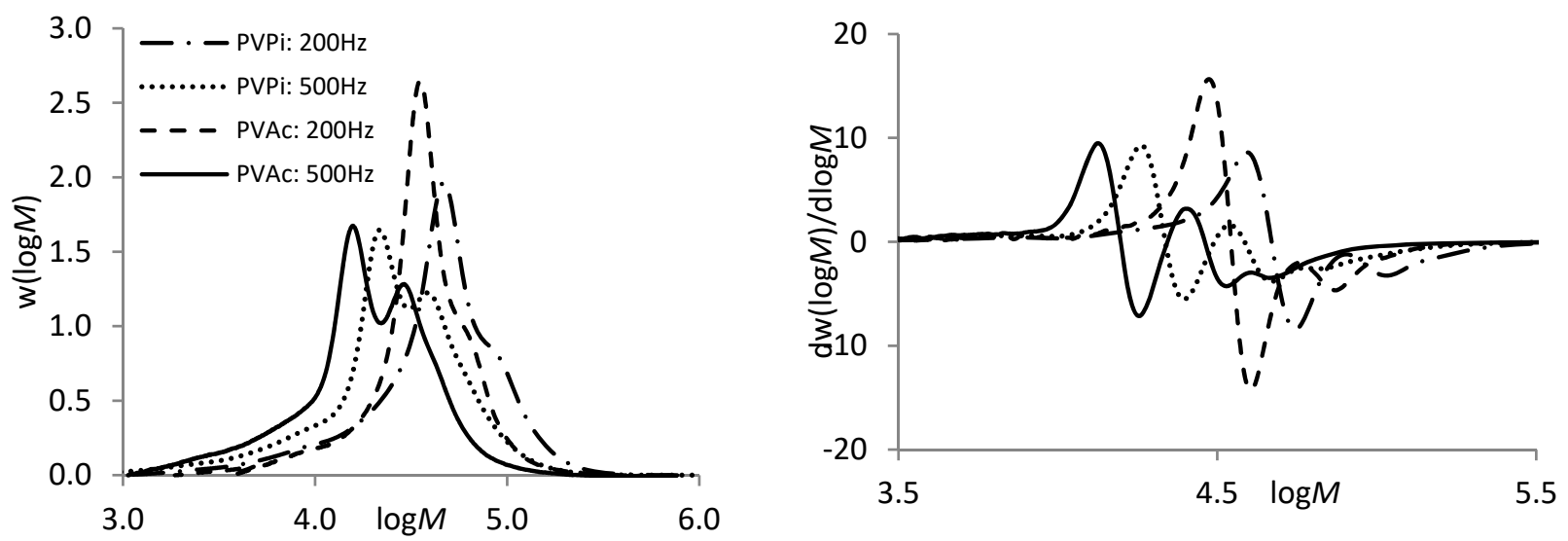

Figure 5. MMD and corresponding first derivative plots for poly(VAc) and poly(VPi) produced by PLP at 200 and $500 \mathrm{~Hz}$ pulse repetition rate at $50^{\circ} \mathrm{C}$.

The trends observed for VPi - a significant increase in PLP-determined $k_{\mathrm{p}}$ values with p.r.r., as well as a corresponding increase in observed activation energy - were also found in our recent study of VAc propagation kinetics. ${ }^{[10]}$ In that paper, we proposed head-to-head addition as a possible explanation for the findings, and accompanied the experimental work with a detailed simulation study, with key points summarized below: 
- In the absence of head-to-head addition $\left(k_{\mathrm{p} 12}=k_{\mathrm{p} 21}=k_{\mathrm{p} 22}=0\right)$, simulations indicated that only a small increase in estimated VAc $k_{\mathrm{p}}$ with p.r.r. would occur from analysis of the resulting MMDs. This increase, caused by peak broadening and approach to the high termination limit, was not large enough to explain the $20-25 \%$ increase found experimentally.

- The ratio of head-to-head to head-to-tail addition $\left(k_{\mathrm{p} 12} / k_{\mathrm{p} 11}\right.$, see Figure 1 and eq 1$)$ must be set to a value of $0.01-0.02$, in order to match the level of head-to-head defects reported in vinyl ester polymers. ${ }^{[15,20]}$

- The apparent dependence of $k_{\mathrm{p}}$ on p.r.r. could be matched only if the rates of addition of monomer to the "tail" radical $\left(k_{\mathrm{p} 21}\right.$ and $\left.k_{\mathrm{p} 22}\right)$ was reduced by a factor of 50 to 100 compared to the rate of head-to-tail addition. With these parameter values a significant fraction of the radicals $(\sim 30 \%)$ were predicted to be in the inverted "tail" state. However, this prediction is in conflict with the EPR study of VAc by Kattner and Buback, ${ }^{[19]}$ in which only the "head" radical structure was observed.

- The simulations for VAc were unable to replicate the experimentally-observed increase in activation energy. They did indicate, however, that the PLP-measured $k_{\mathrm{p}}$ values provided a better measure of $\boldsymbol{k}_{\mathbf{P}}^{\mathbf{a v}}$ than of $k_{\mathrm{p} 11}$ (see Eq. 1).

As the simulation study for VAc did not lead to conclusive results (while head-to-head addition must occur, it is not certain what impact the mechanism has on the PLP-measured $k_{\mathrm{p}}$ values), it has not been repeated for VPi. In addition, although all of the vinyl esters (including vinyl butyrate, vinyl valerate, vinyl caproate and vinyl benzoate) studied by Hayashi and Otsu ${ }^{[20]}$ exhibited the same level of head-to-head addition as VAc, no literature study of the mechanism specific to VPi could be found. Thus, while head-to-head addition likely occurs, the possible 
influence of the reaction on the structure of PLP-determined MMDs remains a topic for future study.
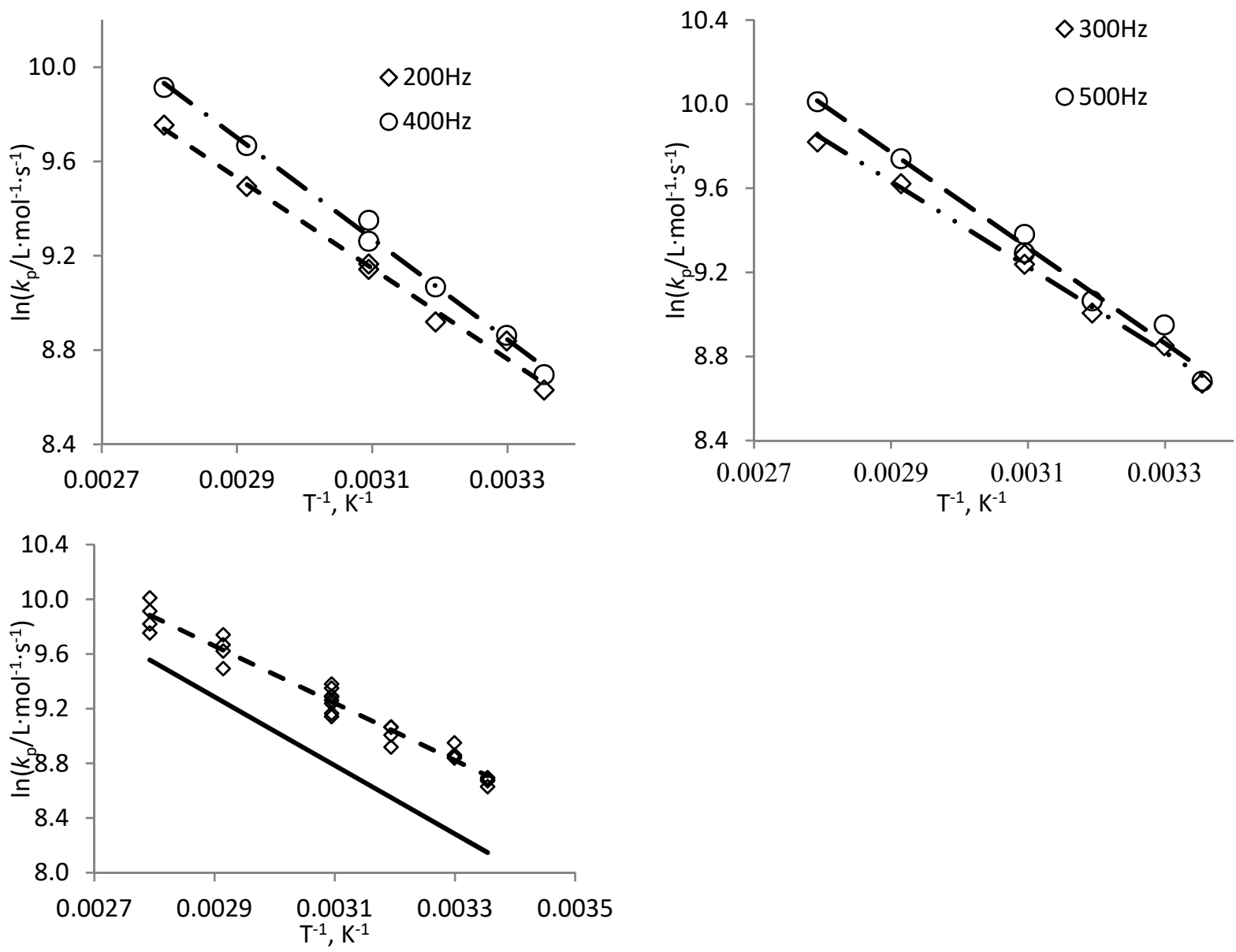

Figure 6. Arrhenius plots of $\mathrm{VPi}$ apparent propagation rate coefficients for experiments conducted at 200 and $400 \mathrm{~Hz}$ (top left), and 300 and $500 \mathrm{~Hz}$ (top right). Global fit Arrhenius plot including all data $(\diamond,---)$ in comparison with VAc $(-)^{[10]}$ (bottom). Best-fit Arrhenius parameters are summarized in Table 2.

Accordingly, a combined fit of the complete data set $(200-500 \mathrm{~Hz})$ has alse been performed and compared to the corresponding VAc fit ${ }^{[10]}$ in Figure 6 . The estimated activation energy for VPi $\left(17.4 \pm 0.7 \mathrm{~kJ} \cdot \mathrm{mol}^{-1}\right)$ is slightly lower than that for VAc $\left(20.9 \pm 0.9 \mathrm{~kJ} \cdot \mathrm{mol}^{-1}\right) \cdot{ }^{[10]}$ A similar but smaller decrease in activation energy has been found with increasing ester size in the methacrylate family. ${ }^{[5]}$ However, the effect of the tert-butyl group is not clear from existing 
literature; while an early PLP-SEC study reported a value of $27.7 \mathrm{~kJ} \cdot \mathrm{mol}^{-1[25]}$ for $t$-butyl methacrylate $(t \mathrm{BMA})$, a later more systematic examination showed no difference in activation energy $\left(22.1 \mathrm{~kJ} \cdot \mathrm{mol}^{-1}\right)^{[26]}$ compared to $n$-butyl methacrylate $(n \mathrm{BMA})\left(22.9 \mathrm{~kJ} \cdot \mathrm{mol}^{-1}\right)^{[5]}$ or methyl methacrylate (MMA) $\left(22.4 \mathrm{~kJ} \cdot \mathrm{mol}^{-1}\right) .{ }^{[4]}$ The $50 \%$ increase found between the $50{ }^{\circ} \mathrm{C} k_{\mathrm{p}}$ values for bulk VPi vs. VAc $\left(10400\right.$ vs. $\left.6600 \mathrm{~L} \cdot \mathrm{mol}^{-1} \cdot \mathrm{s}^{-1}\right)$ is also higher than that for the corresponding methacrylate analogs: $836^{[25]}$ and $642^{[26]}$ for $t$ BMA, $756^{[5]}$ for $n$ BMA and $648^{[4]}$ for MMA (all values in units of $\mathrm{L} \cdot \mathrm{mol}^{-1} \cdot \mathrm{s}^{-1}$ ). It is important to note that these PLP-SEC values for bulk VPi $k_{\mathrm{p}}$ are more than $50 \%$ higher than those reported for VPi in heptane measured by the EPR technique. ${ }^{[13]}$ However, the results are in reasonable agreement with recent values determined at the University of Potsdam using PLP-SEC at 50 and $100 \mathrm{~Hz}$ (Table 2). ${ }^{[24]}$

To further investigate the discrepancy with the values determined by EPR, PLP-SEC experiments of both VAc and VPi were conducted in 50 vol\% heptane and ethyl acetate (EAc) solvents at $50{ }^{\circ} \mathrm{C}$. Heptane was chosen to match the conditions of the EPR study, while the more polar EAc has been chosen as a solvent for ongoing small-scale batch experiments, as poly(VAc) was observed to precipitate out of heptane at higher conversions. With full experimental details provided as Supplemental Information, no major solvent effects on $k_{\mathrm{p}}$ were found. Within the limited data set, the VPi $k_{\mathrm{p}}$ values in solution were within $20 \%$ of that measured in bulk, with values higher in heptane and lower in EAc. Differences in VAc $k_{\mathrm{p}}$ values were also checked, with the value measured for EAc within $10 \%$, and the value in heptane $15 \%$ higher than for bulk VAc. Based upon these $k_{\mathrm{p}}$ determinations by PLP-SEC in solution, we conclude that the $k_{\mathrm{p}}$ values determined by EPR are not of sufficient reliability; although care was taken in that study, the technique is prone to systematic errors caused by calibration. ${ }^{[27-29]}$ 
PLP-SEC was also used in an attempt to study the propagation kinetics of VBz, another member of the vinyl ester monomer family. Surprisingly, no PLP structure was observed over a broad range of conditions examined, including significant variations in p.r..r $(2$ to $500 \mathrm{~Hz})$ and photoinitiator concentrations at 50 and $90{ }^{\circ} \mathrm{C}$ (see Supporting Information). The low reactivity of VBz has been reported previously in the literature, ${ }^{[30-32]}$ with the cause of the reduced rate still not entirely resolved. Ham and Ringwald ${ }^{[30]}$ first proposed that $\mathrm{VBz}$ monomer could copolymerize with itself through radical attack of the aromatic ring to form a more stabilized radical structure. This reaction would lead to a branched structure, discredited by further studies which indicated that addition to the benzene ring does not occur. ${ }^{[33-34]}$ Thus, Santee et al. ${ }^{[34]}$ proposed that the propagating radical can reversibly complex with the aromatic ring, with the resulting adduct radical able to terminate with other radicals but not propagate. However, there is still arguments in literature about whether the aromatic ring is activated through an intramolecular or an intermolecular complex. ${ }^{[34-35]}$ Although the exact mechanism is uncertain, the reduced reactivity of $\mathrm{VBz}$ is consistent with results obtained from an ongoing study using small-scale batch experiments. As shown in Figure 78, at $60{ }^{\circ} \mathrm{C}$ with $1.0 \mathrm{wt} \%$ 2,2'azobis-(2methylbutyronitrile) (V-67) initiator and 50 vol\% EAc solvent, VBz reaches a conversion of less than $5 \%$ in 60 minutes, compared to $34 \%$ for VAc. The polymerization of VPi is even faster, with $93 \%$ conversion reached in 40 minutes. The slight upward curvature of the VPi results indicates an increased rate due to gel effect, despite the presence of the solvent. This trend observed in the relative polymerization rate match the differences in $k_{\mathrm{p}}$ values seen by the PLP study. Further batch experiments, including analysis and modeling of the polymer MMDs, are underway. 


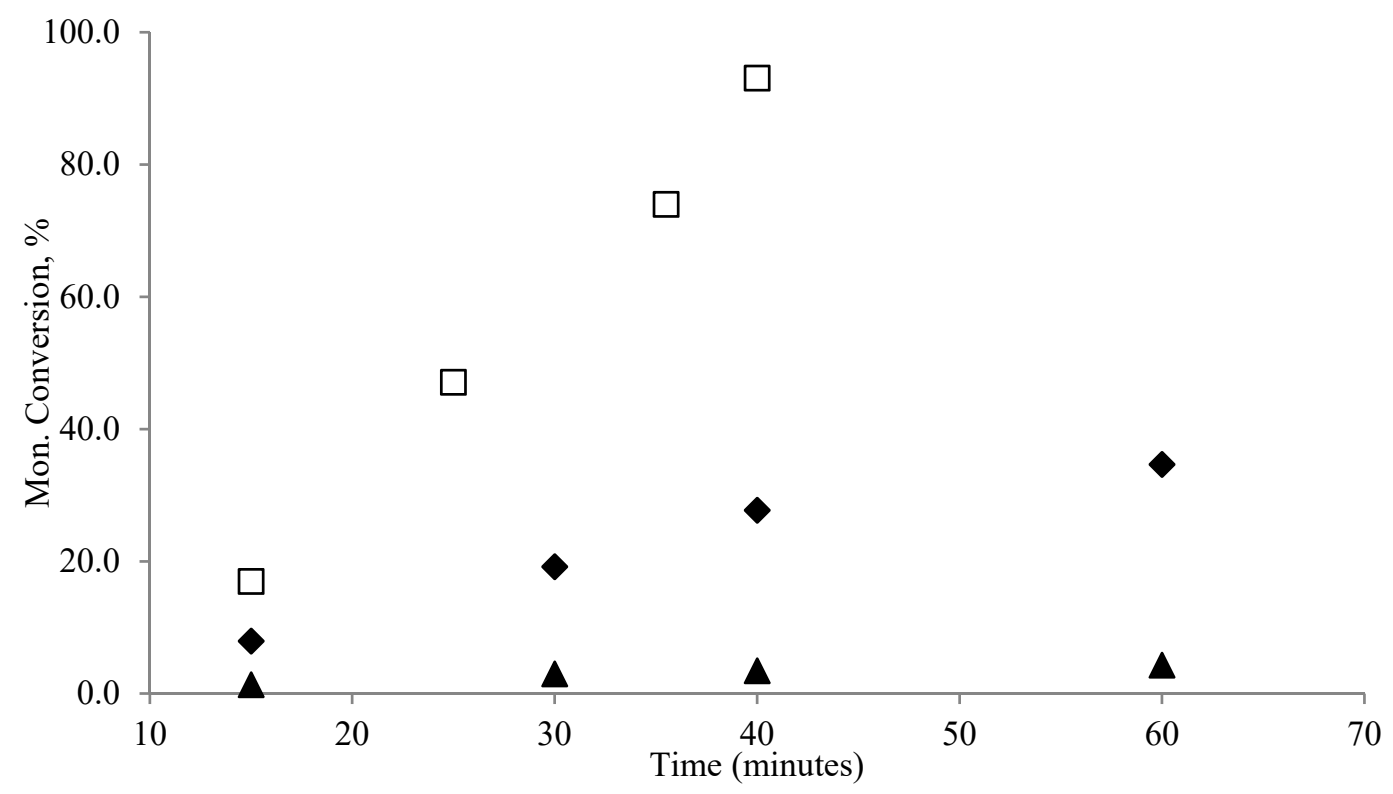

Figure 78. Monomer conversion profiles of VPi $(\square)$, VAc $(\diamond)$ and VBz $(\boldsymbol{\Delta})$ obtained by smallscale batch polymerizations in EAc solution at $60{ }^{\circ} \mathrm{C}$ with $1.0 \mathrm{wt} \% \mathrm{~V}-67$ initiator.

\section{Conclusions}

The PLP technique has been applied to systematically examine the radical propagation homopolymerization kinetics of $\mathrm{VPi}$ and $\mathrm{VBz}$ in the temperature range of $25-85{ }^{\circ} \mathrm{C}$ and the solution polymerization of VPi and VAc at $50{ }^{\circ} \mathrm{C}$. The radical propagation rate coefficient, $k_{\mathrm{p}}$, measured for bulk VPi increases significantly with the laser pulse repetition rate, in a similar trend as seen for VAc, with higher $k_{\mathrm{p}}$ value for VPi than VAc at the same p.r.r. This observation might result from the effect of head-to-head addition that occurs during vinyl ester polymerizations. The $k_{\mathrm{p}}$ values obtained for solution (both in heptane and EAc) polymerization of VPi and VAc were within $20 \%$ of that for bulk, with the limited data making it not possible to determine if there was a significant shift. However, it is clear that the difference in VPi $k_{\mathrm{p}}$ between the current PLP study and the values previously determined by $\mathrm{EPR}^{[13]}$ cannot be attributed to a solvent effect. 
Although the propagation kinetics of VBz could not be determined due to lack of PLP structure in the resulting MMDs, small-scale batch solution polymerizations confirm a much lower rate of reaction compared to VAc and VPi and demonstrate a consistent trend in rates of conversion with the $k_{\mathrm{p}}$ values determined by PLP. Further batch experiments are being conducted to support kinetic model development, with an emphasis on the influence of long-chain branching on polymer MMDs.

Acknowledgment: We thank E. I. du Pont de Nemours and Co. and the Natural Sciences and Engineering Research Council of Canada for financial support of this work.

Supporting Information Available: PLP-generated MMDs and corresponding first derivative plots, as well as tables summarizing operating conditions, SEC results and $k_{\mathrm{p}}$ estimates for all PLP/MMD experiments. 


\section{References}

[1] O. F. Olaj, I. Bitai, F. Hinkelmann, Makromol. Chem. 1987, 188, 1689.

[2] S. Beuermann, M. Buback, Prog. Polym. Sci. 2002, 27, 191.

[3] M. Buback, R. G. Gilbert, R. A. Hutchinson, B. Klumperman, F.-D. Kuchta, B. G. Manders, K. F. O’Driscoll, G. T. Russell, J. Schweer, Macromol. Chem. Phys. 1995, 196, 3267.

[4] S. Beuermann, M. Buback, T. P. Davis, R. G. Gilbert, R. A. Hutchinson, O. F. Olaj, G. T. Russell, J. Schweer, A. M. van Herk, Macromol. Chem. Phys. 1997, 198, 1545.

[5] S. Beuermann, M. Buback, T. P. Davis, R. G. Gilbert, R. A. Hutchinson, A. Kajiwara, B. Klumperman, G. T. Russell, Macromol. Chem. Phys. 2000, 201, 1355.

[6] S. Beuermann, M. Buback, T. P. Davis, N. García, R. G. Gilbert, R. A. Hutchinson, A. Kajiwara, M. Kamachi, I. Lacík, G. T. Russell, Macromol. Chem. Phys. 2003, 204, 1338.

[7] J. M. Asua, S. Beuermann, M. Buback, P. Castignolles, B. Charleux, R. G. Gilbert, R. A. Hutchinson, J. R. Leiza, A. N. Nikitin, J. P. Vairon, A. M. Van Herk, Macromol. Chem. Phys. 2004, 205, 2151.

[8] C. Barner-Kowollik, S. Beuermann, M. Buback, P. Castignolles, B. Charleux, M. L. Coote, R. A Hutchinson, T. Junkers, I. Lacik, G. T. Russell, M. Stach, A. M. van Herk, Polym. Chem. 2014, 5, 204.

[9] R. A. Hutchinson, D. A. Paquet, J. H. McMinn, S. Beuermann, R. E. Fuller, C. Jackson, Dechema Monogr. 1995, 131, 467.

[10] O. Monyatsi, A. N. Nikitin, R. A. Hutchinson, Macromolecules 2014, 47, 8145.

[11] T. Junkers, D. Voll, C. Barner-Kowollik, e-Polymers. 2009, 076, 1.

[12] R. Balic, R. G. Gilbert, M. D. Zammit, T. P. Davis, C. M. Miller, Macromolecules 1997, 30, 3775 .

[13] N. Kubota, A. Kajiwara, P. B. Zetterlund, M. Kamachi, J. Treurnicht, M. P. Tonge, R. G. Gilbert, B. Yamada, Macromol. Chem. Phys. 2007, 208, 2403.

[14] S. Beuermann, Macromol. Rapid Commun. 2009, 30, 1066.

[15] P. J. Flory, F. S. Leutner, J. Polym. Sci. 1948, 3, 880.

[16] A. N. Morin, C. Detrembleur, C. Jérôme, P. De Tullio, R. Poli, A. Debuigne, Macromolecules 2013, 46, 4303. 
[17] M. N. Islam, Y. Haldorai, V. H. Nguyen, J.-J. Shim, Eur. Polym. J. 2014, 61, 93.

[18] R.A. Hutchinson, J. R. Richards, M. T. Aronson, Macromolecules 1994, 27, 4530.

[19] H. Kattner, M. Buback, Macromol. Chem. Phys. 2014, 215, 1180.

[20] K. Hayashi, T. Ostu, Makromol. Chem. 1969, 127, 54.

[21] M. Dossi, K. Liang, R. A. Hutchinson, D. Moscatelli, J. Polym. Sci. Part B Polym. Chem. 2010, 114, 4213.

[22] M. Nerkar, J. A. Ramsay, B. A. Ramsay, M. Kontopoulou, R. A. Hutchinson, J. Polym. Environ. 2013, 21, 24.

[23] G. M. Burnett, W. W. Wright, Trans. Faraday Soc. 1953, 49, 1108.

[24] S. Beuermann correspondence. Data from J. Roberg, BSc. Thesis, University of Potsdam (Potsdam), 2010.

[25] P. Pascal, M. A. Winnik, D. H. Napper, R. G. Gilbert, Makromol. Chem. Rapid Commun. 1993, 14, 213.

[26] G. E. Roberts, T. P. Davis, J. P. A. Heuts, G. E. Ball, Macromolecules 2002, 35, 9954.

[27] M. Kamachi, A. Kajiwara, Macromol. Chem. Phys. 2000, 201, 2160.

[28] M. Kamachi, J. Polym. Sci. Part A: Polym. Chem. 2002, 40, 269.

[29] T. Noda, Y. Morishima, M. Kamachi, A. Kajiwara, Macromolecules 1998, 31, 9078.

[30] G. E. Ham, E. L. Ringwald, J. Poly. Sci. 1951, 8, 91.

[31] N. Beredjick, J. Appl. Poly. Sci. 1965, 9, 439.

[32] M. Kamachi, J. Satoh, D. J. Liaw, S.-I. Nozakura, Macromolecules 1977, 10, 501.

[33] G. A. Mortimer, L. C. Arnold, J. Am. Chem. Soc. 1962, 84, 4987.

[34] G. F. Santee, R. H. Marchessault, H. G. Clark, J. J. Kearny, V. Stannett, Makromol. Chem. 1964, 73, 177.

[35] M. Kamachi, J. Satoh, D. J. Liaw, Poly. Bull. 1979, 1, 581. 


\title{
Vinyl Pivalate Propagation Kinetics in Radical Polymerization
}

\author{
Otlaatla Monyatsi, Robin A. Hutchinson*
}

The propagation kinetics of VPi and VBz were studied using the PLP-SEC technique. The $k_{\mathrm{p}}$ value for VPi is $\sim 50 \%$ higher than that of VAc, but shows the same apparent dependence on laser pulse repetition rate, possibly due to the influence of head-to-head addition on vinyl ester kinetics.

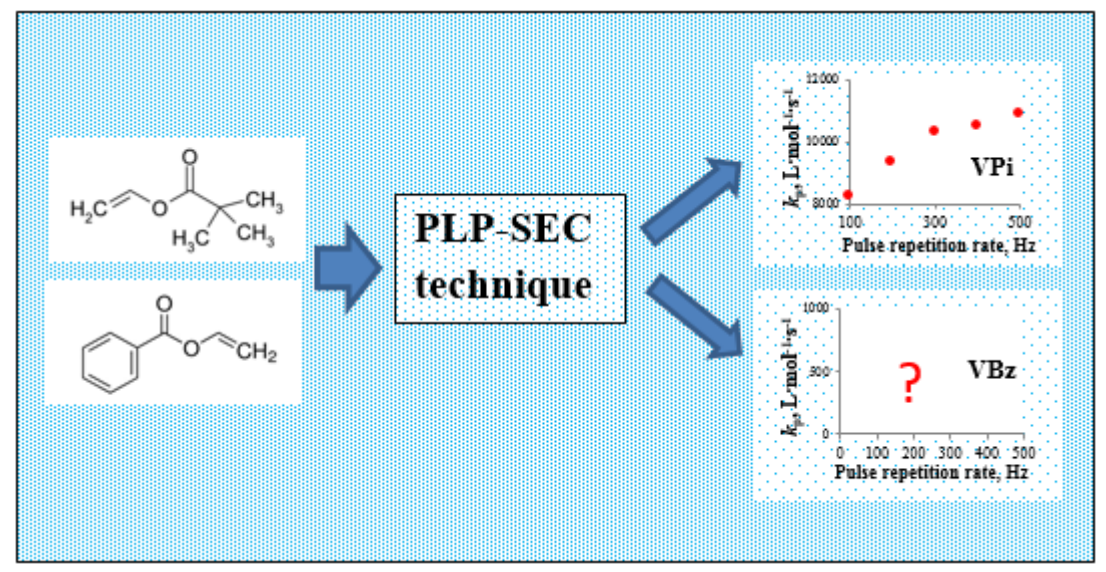

